\title{
Fighting inactivity to improve health: A short commentary
}

\author{
Gyrd O. Gjevestad $^{1,2}$, Stine M. Ulven ${ }^{1}$ and Kirsten B. Holven ${ }^{1,3 *}$
}

${ }^{1}$ Department of Nutrition, Institute of Basic Medical Sciences, Blindern, 0317 University of Oslo, Norway

${ }^{2}$ TINE SA, Centre for Research and Development, Kalbakken, 0902 Oslo, Norway

${ }^{3}$ National Advisory Unit on Familial Hypercholesterolemia, Department of Endocrinology, Morbid Obesity and Preventive Medicine, Oslo University Hospital, Nydalen, 0424 Oslo, Norway

\begin{abstract}
Physical inactivity has been identified as the fourth leading risk factor for global mortality, causing around 3.2 million deaths each year. It increases the risk of developing diseases such as cardiovascular diseases, cancers, diabetes type 2 and obesity. However, considerable improvements in public health may be possible even with a small increase in physical activity level across all age groups. Great efforts should therefore be made, both at governmental and individual level, to encourage people to walk the stairs instead of taking the elevator, walk or ride a bike instead of driving the car or take an afternoon walk instead of spending time in front of the television. In this short commentary, overall health benefits of regular physical activity will be briefly summarized. We will also touch upon physical training, including strength exercise, as tools to improve health outcomes, and the use of self-monitoring as a device to assess physical activity levels.
\end{abstract}

\section{Introduction}

Physical inactivity has been identified as the fourth leading risk factor for global mortality, causing around 3.2 million deaths each year [1]. Physical activity on the other hand reduces the risk of developing chronic diseases such as cardiovascular diseases, obesity and diabetes type 2 and cancers [2-4]. It prevents premature death [5,6] and improves quality of life [7]. In addition, bones and skeletal muscles are strengthened [8], and cognitive functions improved $[9,10]$. Physical activity seems to be equally effective as medication in improving depression [11]. In fact, no medicine has ever proven to be as effective as regular physical activity on the accumulated reduced risk of developing chronically related diseases [12], making increased physical activity level across all age groups a powerful tool to improve public health [13].

\section{Recommended levels of physical activity}

The World Health Organization recommends adults (18-64 years) to be moderately physical active for a least 150 minutes, or vigorously active for at least 75 minutes, throughout the week [7]. Children (517 years) are advised to accumulate at least 60 minutes of moderate to vigorous physical activity per day [7]. However, there seems to be a dose-response relationship between physical activity and health benefits in healthy subjects, increasing the health benefits with increased activity levels [14]. A recently published cross-sectional study showed that walking or riding a bike to work reduced total body fat compared to driving, even though the intensity of the activity was low [15]. In another study it was shown that reducing the amount of walking from 6000 to 1500 steps daily negatively affected insulin sensitivity, reduced lean mass and increased fat mas in both young and older subjects $[16,17]$. Thus, every minute of physical activity contributes to better health [2]. However, a recent meta-analysis showed that 60-75 minutes of vigorous walking daily was needed to eliminate the detrimental effects of being inactive for eight hours every day [6].

\section{Metabolic effects of physical activity}

The molecular mechanisms behind the positive health effects of being physically active are not fully elucidated, but increased insulin sensitivity, reduced levels of triglycerides and reduced blood pressure $[18,19]$ are some of the positive observed health effects of increased physical activity levels (Figure 1). There is also evidence indicating that regular physical activity reduces the level of markers known to be involved in chronic-low grade inflammation [20-22], a common contributor to several non-communicable diseases. However, more research is needed to fully understand the mechanisms behind the positive health effects of exercise.

\section{Endurance training to improve aerobic capacity}

Vigorous physical activity or endurance training, such as running, fast cycling or fast swimming, is needed to increase the aerobic capacity (Table 1) or maximal oxygen uptake $\left(\mathrm{VO}_{2 \max }\right)$. Increased aerobic capacity will increase the heart's ability to deliver oxygen to the working skeletal muscle, thereby increasing the ability of the skeletal muscles to perform work over time. Two types of aerobic training have largely been represented in the literature; chronic endurance training (50-80\% of $\left.\mathrm{VO}_{2 \max }\right)$ and high-intensity interval training $\left(\sim 90 \%\right.$ of $\left.\mathrm{VO}_{2 \max }\right)$. Highintensity interval training may be performed as four minutes repeated intervals with an active period of three minutes between each interval [23], while the intensity in chronic endurance training is quite stable. Both methods may be adapted to different activity levels and types of activities, preferably with increased intensity as the aerobic capacity improves. Increased insulin sensitivity and reduced blood pressure has been shown with both methods, but high-intensity interval training may be superior increasing the $\mathrm{VO}_{2 \max }$ [23]. However, the safety of high-intensity interval training has been questioned for non-healthy

Correspondence to: Kirsten B. Holven, Department of Nutrition, Institute of Basic Medical Sciences, P.O. Box 1046, Blindern, 0317 University of Oslo, Norway, Tel: +47-22851361; E-mail: k.b.holven@medisin.uio.no

Key words: disease prevention, interval exercise, self-monitoring, strength training Received: March 14, 2017; Accepted: April 10, 2017; Published: April 13, 2017 
Table 1. Definitions.

\begin{tabular}{|l|l|}
\hline Physical activity & $\begin{array}{l}\text { Any bodily movement produced by skeletal muscles that requires energy expenditure. This includes sports, exercise and other activities such as playing, } \\
\text { walking, doing household chores, gardening, and dancing [35]. }\end{array}$ \\
\hline Exercise & Physical activity that is planned, structured, and repetitive for the purpose of conditioning any part of the body [35]. \\
\hline Aerobic capacity & The maximum amount of oxygen, $\mathrm{O}_{2},($ inn $\mathrm{ml})$ an athlete can use in one minute/kg of body weight, measured as maximum oxygen uptake $\left(\mathrm{VO}_{2 \max }\right)[36]$. \\
\hline
\end{tabular}

subjects, as the majority of studies investigating the effects of highintensity interval training have included young, healthy subjects only. More research is therefore warranted to elucidate the effects of highintensity interval training in older and diseased populations [24]. For non-healthy people it may therefore be appropriate to consult a physician before starting heavy conditioning programs. It should be noted that extreme exercise programs may be associated with some negative health effects, such as increased risk of developing upper tract infections and asthma $[25,26]$.

\section{Self-monitoring of physical activity levels}

To motivate people to change their way of living and to include physical activity into their daily lives, have been shown difficult. Behavioral science is a discipline by itself and it will not be extensively touched upon in this paper. However, to be able to increase physical activity levels, both at the individual level and at the population level, it is crucial to understand how people become motivated to change behavior, and how it is advisable to work at a regulatory level to promote

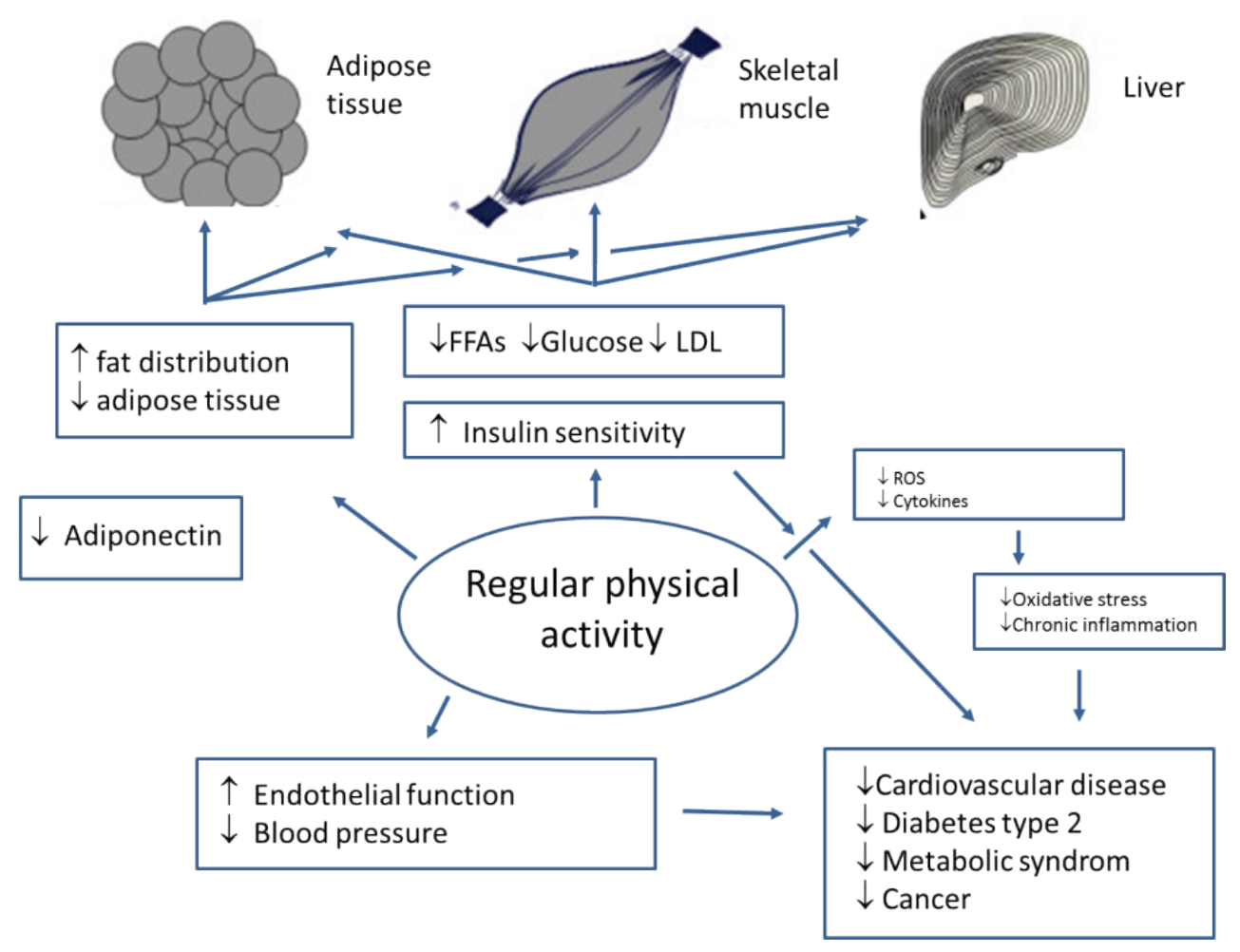

LDL: low density lipoprotein; ROS: reactive oxygen species; FFAs: free fatty acids

Figure 1. Illustration of the major metabolic effects of regular physical activity.

\section{Strength exercise to promote muscle growth}

Strength exercise is especially important for building muscles (hypertrophy). Muscle mass will gradually decrease from the age of 30 years and without exercise, $0.5-1 \%$ of the muscle mass may be lost every year [27]. Loss of muscle mass and muscle strength may potentially lead to sarcopenia, which is associated with impaired functionality and increased mortality among older people [28]. Randomized controlled trials show that resistance exercise provides the best protection against sarcopenia $[29,30]$. A stronger body will also make it easier to perform daily activities [31], improve quality of life, potentially enabling older people to extent the period living at home, and spearing the society for a substantial amount of money [32]. Strength exercise programs should therefore be an important part of disease recovery for all, but especially for older people as they rapidly loose muscle mass when immobilized. long lasting behavioral changes. A relatively new phenomenon is selfmonitoring of physical activity or inactivity. Several devises for selfmonitoring already exist on the market. These devises may be helpful tools to increase the level of physical activity [33]. Self-monitoring is shown to be one of several factors important to drive changes at the individual level [34] as it increases the individual's personal responsibility, promote independence, and makes it possible to create individual pathways toward goal achievement by taking an active role [33]. To encourage the use of these novel technologies as an aid for behavioral changes in physical activity levels and sedentary behavior seems to be warranted, both at individual level and on a larger scale.

\section{Concluding remarks and further perspectives}

Despite all the positive health effects observed from regular physical activity, there is a great challenge to increase the activity levels across all 
populations. Continued research to increase the knowledge about the mechanisms of physical activity on health, including different exercise schemes, and a better understanding of factors that motivates people to increase their physical activity levels, in different populations and among different age groups, are therefore warranted. Technologies to individually monitoring physical activity levels may promote increased physical activity levels at the individual level, and should be developed further.

\section{Authors contribution}

Gjevestad drafted the original manuscript and all authors critically read and revised it. All authors approved the final manuscript.

\section{Conflict of interest}

K.B.H. and S.M.U. report no conflict of interest. G.O.G. is employed at TINE SA.

\section{Funding}

This work was supported by grants from the Throne Holst Foundation for Nutrition Research, the University of Oslo.

\section{References}

1. Organisation WH (Available from: http://www.who.int/dietphysicalactivity/factsheet inactivity/en/).

2. Warburton DE, Nicol CW, Bredin SS (2006) Health benefits of physical activity: the evidence. CMAJ 174: 801-809. [Crossref]

3. de Sousa CV, Sales MM, Rosa TS, Lewis JE, de Andrade RV, et al. (2017) The Antioxidant Effect of Exercise: A Systematic Review and Meta-Analysis. Sports Med 47: 277-293. [Crossref]

4. Wilmot EG, Edwardson CL, Achana FA, Davies MJ, Gorely T, et al. (2012) Sedentary time in adults and the association with diabetes, cardiovascular disease and death: systematic review and meta-analysis. Diabetologia 55: 2895-905. [Crossref]

5. Ladenvall P, Persson CU, Mandalenakis Z, Wilhelmsen L, Grimby G, et al. (2016) Low aerobic capacity in middle-aged men associated with increased mortality rates during 45 years of follow-up. Eur J Prev Cardiol 23: 1557-1564. [Crossref]

6. Ekelund U, Steene-Johannessen J, Brown WJ, Fagerland MW, Owen N, et al. (2016) Does physical activity attenuate, or even eliminate, the detrimental association of sitting time with mortality? A harmonised meta-analysis of data from more than 1 million men and women. Lancet 388: 1302-1310. [Crossref]

7. Organization WH (2004) Global Strategy on Diet, Physical Activity and Health.

8. Bauman A, Merom D, Bull FC, Buchner DM, Fiatarone Singh MA (2016) Updating the Evidence for Physical Activity: Summative Reviews of the Epidemiological Evidence, Prevalence, and Interventions to Promote "Active Aging". Gerontologist 56 S268-S280. [Crossref]

9. Vivar C, Potter MC, van Praag H (2013) All about running: synaptic plasticity, growth factors and adult hippocampal neurogenesis. Curr Top Behav Neurosci 15: 189-210. [Crossref]

10. Moritani T, Akamatsu Y (2015) Effect of Exericse and Nutrition upon LifestyleRelated Disease and Cognitive Function. J Nutr Sci Vitaminol (Tokyo) 61: S122-S124. [Crossref]

11. Cooney GM, Dwan K, Greig CA, Lawlor DA, Rimer J, et al. (2013) Exercise for depression. Cochrane Database Syst Rev: CD004366. [Crossref]

12. Fiuza-Luces C, Garatachea N, Berger NA, Lucia A (2013) Exercise is the real polypill. Physiology (Bethesda) 28: 330-358. [Crossref]

13. Murray CJ, Richards MA, Newton JN, Fenton KA, Anderson HR, et al. (2013) UK health performance: findings of the Global Burden of Disease Study 2010. Lancet 381: 997-1020. [Crossref]

14. Helsedirektoratet. Anbefalinger for fysisk aktivitet. (Availabke from: https:// helsedirektoratetno/folkehelse/fysisk-aktivitet/anbefalinger-fysisk-aktivitet).

15. Flint E, Cummins S (2016) Active commuting and obesity in mid-life: cross-sectional, observational evidence from UK Biobank. The lancet Diabetes \& endocrinology 4: 420-435.
16. Breen L, Stokes KA, Churchward-Venne TA, Moore DR, Baker SK, et al. (2013) Two weeks of reduced activity decreases leg lean mass and induces "anabolic resistance" of myofibrillar protein synthesis in healthy elderly. J Clin Endocrinol Metab 98: 26042612. [Crossref]

17. Olsen RH, Krogh-Madsen R, Thomsen C, Booth FW, Pedersen BK (2008) Metabolic responses to reduced daily steps in healthy nonexercising men. JAMA 299: 1261-1263. [Crossref]

18. Cornelissen VA, Smart NA (2013) Exercise training for blood pressure: a systematic review and meta-analysis. J Am Heart Assoc 2: e004473. [Crossref]

19. Teixeira-Lemos E, Nunes S, Teixeira F, Reis F (2011) Regular physical exercise training assists in preventing type 2 diabetes development: focus on its antioxidant and anti-inflammatory properties. Cardiovasc Diabetol 10: 12. [Crossref]

20. Gleeson M, Bishop NC, Stensel DJ, Lindley MR, Mastana SS, et al. (2011) The antiinflammatory effects of exercise: mechanisms and implications for the prevention and treatment of disease. Nat Rev Immunol 11: 607-615. [Crossref]

21. Nimmo MA, Leggate M, Viana JL, King JA (2013) The effect of physical activity on mediators of inflammation. Diabetes Obes Metab 3: 51-60. [Crossref]

22. Kasapis C, Thompson PD (2005) The effects of physical activity on serum C-reactive protein and inflammatory markers: a systematic review. $J$ Am Coll Cardiol 45: 15631569. [Crossref]

23. Wisløff U, Coombes JS, Rognmo Ø (2015) CrossTalk proposal: High intensity interval training does have a role in risk reduction or treatment of disease. J Physiol 593: 52155217. [Crossref]

24. Holloway TM, Spriet LL (2015) CrossTalk opposing view: High intensity interval training does not have a role in risk reduction or treatment of disease. J Physiol 593 5219-5221. [Crossref]

25. Langdeau JB, Boulet LP (2001) Prevalence and mechanisms of development of asthma and airway hyperresponsiveness in athletes. Sports Med 31: 601-616. [Crossref]

26. Morici G, Gruttad'Auria CI, Baiamonte P, Mazzuca E, Castrogiovanni A, et al. (2016) Endurance training: is it bad for you? Breathe (Sheff) 12: 140-147. [Crossref]

27. Goodpaster BH, Park SW, Harris TB, Kritchevsky SB, Nevitt M, et al. (2006) The loss of skeletal muscle strength, mass, and quality in older adults: the health, aging and body composition study. J Gerontol A Biol Sci Med Sci 61: 1059-1064. [Crossref]

28. Cruz-Jentoft AJ, Landi F (2014) Sarcopenia. Clin Med (Lond) 14: 183-186. [Crossref]

29. Law TD, Clark LA, Clark BC (2016) Resistance Exercise to Prevent and Manage Sarcopenia and Dynapenia. Annu Rev Gerontol Geriatr 36: 205-228. [Crossref]

30. Bibas L, Levi M, Bendayan M, Mullie L, Forman DE, et al. (2014) Therapeutic interventions for frail elderly patients: part I. Published randomized trials. Prog Cardiovasc Dis 57: 134-143. [Crossref]

31. Viña J, Tarazona-Santabalbina FJ, Pérez-Ros P, Martínez-Arnau FM, Borras C, et al (2016) Biology of frailty: Modulation of ageing genes and its importance to prevent age-associated loss of function. Mol Aspects Med 50: 88-108. [Crossref]

32. Das P, Horton R (2016) Physical activity-time to take it seriously and regularly. Lancet 388: 1254-1255. [Crossref]

33. Sanders JP, Loveday A, Pearson N, Edwardson C, Yates T, et al. (2016) Devices for Self-Monitoring Sedentary Time or Physical Activity: A Scoping Review. $J$ Med Internet Res 18: e90. [Crossref]

34. Bourke L, Homer KE, Thaha MA, Steed L, Rosario DJ, et al. (2013) Interventions for promoting habitual exercise in people living with and beyond cancer. Cochrane Database Syst Rev : CD010192. [Crossref]

35. Caspersen CJ, Powell KE, Christenson GM (1985) Physical activity, exercise, and physical fitness: definitions and distinctions for health-related research. Public Health Rep 100: 126-131. [Crossref]

36. Howley ET, Bassett DR Jr, Welch HG (1995) Criteria for maximal oxygen uptake: review and commentary. Med Sci Sports Exerc 27: 1292-1301. [Crossref]

Copyright: (C2017 Gjevestad GO. This is an open-access article distributed under the terms of the Creative Commons Attribution License, which permits unrestricted use, distribution, and reproduction in any medium, provided the original author and source are credited. 